\title{
Autophagy: A new treatment strategy for MSC-based therapy in acute kidney injury (Review)
}

\author{
HAOYUAN JIA, YONGMIN YAN, ZHAOFENG LIANG, NITIN TANDRA, \\ BIN ZHANG, JUANJUAN WANG, WENRONG XU and HUI QIAN \\ Key Laboratory of Laboratory Medicine of Jiangsu Province, School of Medicine, \\ Jiangsu University, Zhenjiang, Jiangsu 212013, P.R. China
}

Received March 15, 2017; Accepted November 9, 2017

DOI: $10.3892 / \mathrm{mmr} .2017 .8311$

\begin{abstract}
Acute kidney injury (AKI) is a common and serious medical condition associated with poor health outcomes. Autophagy is a conserved multistep pathway that serves a major role in many biological processes and diseases. Recent studies have demonstrated that autophagy is induced in proximal tubular cells during AKI. Autophagy serves a pro-survival or pro-death role under certain conditions. Furthermore, mesenchymal stem cells (MSCs) have therapeutic potential in the repair of renal injury. This review summarizes the recent progress on the role of autophagy in AKI and MSCs-based therapy for AKI. Further research is expected to prevent and treat acute kidney injury.
\end{abstract}

\section{Contents}

1. Introduction

2. Autophagy in disease

3. Prevention and conventional treatment of AKI

4. MSCs and extracellular vesicles therapy in AKI

5. The role of autophagy in MSCs cell-based therapies

6. Conclusions

\section{Introduction}

Autophagy is imperative in normal and pathological conditions, including inflammation, adaptation to stress, aging, immunity, metabolic and neurodegenerative disorders, and cancer (1-7). Both in vivo animal models and in vitro cell culture studies suggest that autophagy serves a role in the maintenance of renal

Correspondence to: Professor Hui Qian, Key Laboratory of Laboratory Medicine of Jiangsu Province, School of Medicine, Jiangsu University, 301 Xuefu Road, Zhenjiang, Jiangsu 212013, P.R. China

E-mail: 1stmmmlst@163.com

Key words: autophagy, acute kidney injury, mesenchymal stem cells, cell death function under pathological conditions including nephrotoxic drugs treatment or ischemia/reperfusion (I/R) injury $(8,9)$.

Acute kidney injury (AKI) is characterized by tubular cell injury and death that leads to a rapid and progressive loss of renal function, including declined glomerular filtration, accumulation of nitrogenous wastes and imbalance of water, electrolytes and acid-base reactions. AKI is a common disease and constitutes a risk factor for chronic kidney disease (10). The incidence of AKI during an ICU stay ranges from 22 to $67 \%$ (11). Although there is certain progress in basic research and clinical application, AKI with an increasing morbidity and mortality rate and few prevention and treatment approaches, remains a common and serious clinical condition in hospitalized patients (11).

\section{Autophagy in disease}

Autophagy is classified into three subtypes: macroautophagy, chaperone-mediated autophagy, and microautophagy (12). Macroautophagy, generally referred to as autophagy, is well-studied and is the focus of this review. Autophagy is an 'auto-eating' process in a cell where intracellular organelles, proteins, and other macromolecules are sequestered into autophagic vesicles (known as autophagosomes) and then degraded by the hydrolases of lysosomes (13). The formation of autophagosomes involves the following steps: Induction, nucleation and elongation that form a complete isolation membrane. Subsequently, double-membrane autophagosomes with sequestered materials inside fuses with the lysosome and form autolysosomes (Fig. 1). Cytoplasmic constituents are degraded by the lysosomal hydrolases for cyclic utilization (14). The initiation step of autophagosome formation involved the ULK1/2-Atg13-FIP200 complex, which is required for the phagophore membranes. The phagophore membrane PI3K/Vps34 complex containing Vps34, Vps15, Beclin-1 and Atg14 L is recruited for nucleation. Autophagy-related gene 9 (Atg 9) and vacuole membrane protein 1 (VMP1) are necessary for membrane expansion. Atg1-Atg13-Atg17 complex promote Atg9 cycling between the phagophore assembly site (PAS) and non-PAS compartments and aided in localization of Atg9 to the PAS $(15,16)$. Indeed, Atg12-Atg5-Atg16 complex and Atg8/light chain 3-II are two ubiquitin-like conjugation systems that are involved in the elongation and expansion steps during autophagosome formation (17). Mi et al (18) demonstrated that actin 
served a role in autophagosome formation. They demonstrated that polymerized actin puncta were co-localized with DFCP1 [a PtdIns(3)P-binding ER protein that marks omegasomes] and LC3-positive puncta. PtdIns(3)P promoted actin network formation inside membranes, thereby branched actin networks are essential for autophagosomal membrane shaping.

Recent studies have documented the key role of autophagy in normal physiological conditions as well as in pathogenesis conditions. In physiological processes, a low level of basal autophagy occurs to maintain cellular homeostasis. In pathological conditions, cellular stress including hypoxia, cell starvation, oxidant injury, genotoxic agents, and other damaging factors contribute to the induction of autophagy $(19,20)$.

Autophagy has both pro-survival and pro-death functions in gastric cancer cells (21). Autophagy is upregulated in cancer cells to provide nutritive material for cell survival (22). Pla et al (23) demonstrated that autophagy decreased ethanol toxicity in mouse neurons. Autophagy and autophagic flux decreased in aging hearts, stimulation of autophagy alleviated aging-associated pathology in the heart (24). Furthermore, autophagy is considered to play a renoprotective role in kidney injury (25).

\section{Prevention and conventional treatment of AKI}

AKI is mainly caused by $\mathrm{I} / \mathrm{R}$ injury and nephrotoxic drugs which impair renal function Adequate hydration control, maintenance of arterial pressure, pre-emptive use of antioxidants may prevent AKI; few treatments could change the development of AKI (26). Previous studies have demonstrated autophagy serves a role in AKI (27-33).

Autophagy in ischemia reperfusion injury. I/R injury is a leading cause of AKI, which is frequently associated with many clinical conditions but lacks effective therapies (27). Recent studies have reported that autophagy is activated in renal I/R injury in vitro and in vivo models irrespective of the genetic or pharmacological impairment of autophagy (27-35).

In vivo renal I/R injury patterns, pretreated with 3-methyladenine (3-MA, an autophagy inhibitor) or pretreated with rapamycin (an autophagy activator), demonstrated that autophagy served a renoprotective effect by inhibiting apoptosis $(27,28)$ or by decreasing pro-inflammatory cytokines (29). Similar results were reported by Jiang et al (30), indicated that inhibition of autophagy by chloroquine aggravated AKI, whereas the upregulation of autophagy by rapamycin improved lost renal function, further indicating the protective role of autophagy in AKI. In C57BL/6 mice, renal I/R injury is aggravated by the suppression of autophagy using chloroquine and 3-MA (31). Endoplasmic reticulum stress inducer tunicamycin, caused significant Grp78 expression and ameliorating renal I/R injury in vivo by inducing autophagy (32). It was also found that autophagy protects kidneys from I/R injury in vivo, but the exact mechanisms remain to be elucidated.

Pharmacological inhibitors or inducers of autophagy have non-specific effects and therefore previous studies demonstrated the effect of autophagy during renal I/R by using conditional kidney proximal tubule-specific Atg5- or Atg7-knockout mice $(31,33)$. Kimura et al (33) demonstrated that I/R injury increases proximal tubule cell apoptosis in kidney proximal tubule-specific Atg5 mice compared with the wild-type mice. It is also demonstrated that autophagy serves a critical role in maintaining tubular cell integrity during stress conditions (34).

Jiang et al (30) revealed that autophagy was induced earlier than apoptosis in response to hypoxia, in GFP-LC3-transfected tubular cells. Blockade of autophagy by 3-methyladenine or small-interfering RNA knockdown of Beclin-1 and Atg5 (two essential autophagic genes) lead to hypoxia-induced apoptosis in vitro (31). Transfection of small interfering RNAs for heat shock protein 1 have been shown to inhibit cell autophagy and increased apoptosis in GFP-LC3-transfected NRK-52e cells during $\mathrm{H}_{2} \mathrm{O}_{2}$ treatment $(34,35)$. Besides rat tubular cells, Wang et al (36) demonstrated that adenosine monophosphate-activated kinase (AMPK) protected pig renal tubular cells (LLC-PK1) from I/R injury by regulating mTOR pathway in vitro.

On the other hand, excessive stimulation of autophagy has been described to exacerbate I/R injury in the kidney (37). Isaka et al (38) used LC3-GFP transgenic mice and demonstrated that I/R injury promoted the formation of LC3-GFP dots. By contrast, increased B-cell lymphoma (Bcl)-2 protein protected tubular epithelial cells from I/R injury by suppressing autophagy and inhibiting apoptosis (38). Furthermore, overexpression of Bcl-xL and Bcl-2 eliminate both apoptosis and autophagy (39). Suzuki et al (40) used HK-2 cells subjected to hypoxia or activation of reactive oxygen species and demonstrated that compared to normoxic conditions LC3-labeled autophagic vacuoles slightly increased and lysosome-associated membrane protein2-labeled lysosomes markedly increased following $48 \mathrm{~h}$ of hypoxia. Using lysosomal protease inhibitors autophagosomes increased significantly under hypoxia, suggesting that hypoxia highly induces autophagic generation and degradation. Moreover, HK2 cells with Atg7 deletion significantly inhibit $\mathrm{H}_{2} \mathrm{O}_{2}$-induced cell death (40). These results indicate that autophagy may contribute to cell death during renal ischemia-reperfusion injury. In another study it was demonstrated that kidneys of GFP-LC3 transgenic mice that were subjected to $48 \mathrm{~h}$ of cold ischemia in the presence of lysosomal inhibitor bafilomycin A1, the number of apoptotic cells were significantly reduced (41) suggesting that autophagy may serve a role in I/R injury.

Non-coding RNAs, including lncRNA and microRNAs, exhibit an effect on regulating autophagy during I/R injury (42-44). MicroRNAs serve a significant effect in autophagy during kidney $\mathrm{I} / \mathrm{R}$ injury both in vivo and in vitro $(43,44)$. Liu et al $(43)$ demonstrated that miR-34a reduced the autophagic activity and caused injury in $\mathrm{I} / \mathrm{R}$ tubular epithelial cells via a direct binding to the Atg4B 3'-untranslated region. In addition, miR-21 mimics directly targeted Rab11a 3'-UTR reducing beclin-1, LC3-II expression and increased p62 expression in the I/R model. Overexpression of Rab1la weakened the effect of miR-21 mimics and I/R on cell apoptosis (44). In a rat I/R model, pre-treatment with miR-21 inhibitor injection ameliorated the renal injury, and increased the expression of LC3-II and beclin-1 (44). The role of autophagy in I/R damage depends on the injury situation such as the duration of hypoxia, ischemia and reperfusion, and the effect of autophagy in different studies is shown in Table I. 


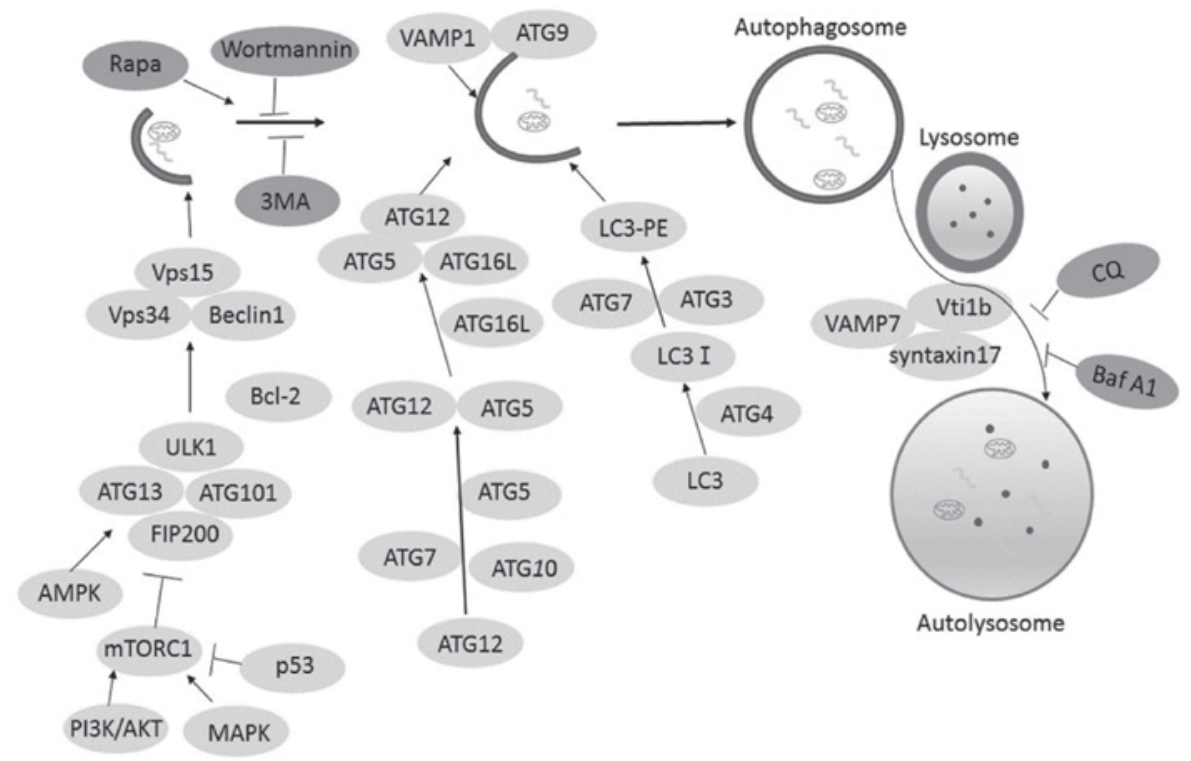

Figure 1. Overview of the autophagy process and its molecular machinery. The formation of autolysosome involves several processes and a number of autophagy-associated genes. PI3K/AKT and MAPK inhibit autophagy by regulating mTOR signaling pathway, p53 serves the opposite effect. AMPK upregulates autophagy by activating ULK1 complex. However, Bcl-2 inhibits autophagy by interacting with Beclin1. Rapamycin promotes the nucleation step of autophagosome, but wortmannin and 3MA inhibit this step. In addition, CQ and Baf A1 impair the autophagic flux by inhibiting the fusion autophagosome and lysosome. PI3K/AKT, phosphatidylinositol 4,5-bisphosphate/RAC-alpha serine/threonine-protein kinase; MAPK, mitogen-activated protein kinase; mTOR, serine/threonine-protein kinase mTOR; AMPK, 5' AMP-activated protein kinase; ULK1, Serine/threonine-protein kinase ULK1; Bcl-2, apoptosis regulator Bcl-2; CQ, chloroquine; BAF, bafilomycin A1; 3MA, 3-methyladenine.

Autophagy in drug-induced acute kidney injury. Cisplatin is a widely used chemotherapeutic drug, with major side effects in kidneys, leading to cell death and tissue damage $(45,46)$. Several studies demonstrated that cisplatin is capable of activating autophagy both in vitro and in vivo AKI models (47-51).

Depending on the experimental conditions, autophagy could act as a mechanism of cytoprotection $(47,48)$. Cisplatin induced an increase of LC3-II expression that is further enhanced by emodin treatment in NRK-52E cells (49). Autophagy activity is increased after $6 \mathrm{~h}$ of cisplatin treatment and began a gradual decrease from $12 \mathrm{~h}$ in proximal tubular cells (RPTCs), which was transiently transfected with GFP-LC3, indicating that autophagy is induced before apoptosis in RPTCs during cisplatin treatment (50). Consistently, using mRFP-LC3-transfected NRK-52E cells it was demonstrated that emodin increased the formation of mRFP-LC3 dots and decreased apoptosis during cisplatin treatment (51). Inhibition of autophagy with either 3-MA or bafilomycin A1 elevated renal proximal tubular cell apoptosis and abolished the protective effects of emodin during cisplatin treatment $(50,51)$, suggesting a renoprotective role of autophagy in cisplatin-induced AKI. HEK cells with Beclin-1 knockdown prevent the formation of GFP-LC3 dots during cisplatin treatment and sensitize cells to cisplatin-induced apoptosis (50). By contrast, overexpressed beclin-1 and Atg5 in LLC-PK1 cells inhibit caspase activation and protecte tubular cells from cisplatin toxicity (51). This further supports that autophagy serves a protective role against cisplatin injury to proximal tubular epithelial cells.

Furthermore, further in vivo studies have affirmed that autophagy serves the same cytoprotective role as in the in vitro findings. An in vivo model autophagy was induced in proximal kidney tubules during cisplatin treatment in C57BL/6 mice (50). Autophagic vesicles were increased in
C57BL/6 mice after cisplatin treatment, as detected by electron microscopy (50). Activation of autophagy by rapamycin ameliorated cisplatin-induced AKI, whereas the inhibition of autophagy by chloroquine aggravated cisplatin-induced AKI in C57BL/6 mice $(31,51)$. In addition, proximal tubule-specific Atg7-deficient mice, which were more sensitive to cisplatin-induced injury compared with the wild-type mice (31).

The activity of autophagy is crucial to protect kidney against chemotherapeutics injury (49). The underlying mechanism of how autophagy protects the kidney from the damage induced by cisplatin is not clearly understood (31). P53 is reported to participate in cisplatin-induced renal cell apoptosis in in vitro and in vivo models (52-58). Feng et al (59) suggested that p53 regulates autophagy. Periyasamy-Thandavan et al (50) demonstrated that pifithrin- $\alpha$, a pharmacological inhibitor of p53, inhibited autophagosome formation during cisplatin treatment in RPTCs. Increased p53 and JNK activation aggravate cisplatin-induced proximal tubular cells apoptosis in PT-Atg7-KO mice (31).

mTORC1 is a critical serine-threonine kinase in the autophagy regulation pathway that negatively regulates autophagy activity (49). However, AMPK inhibited the activity of mTORC1, a AMPK inhibitor compound C significantly suppressed emodin-induced AMPK phosphorylation and LC3 conversion, consequently inhibited the autophagic activity and increased the cisplatin-induced proximal tubular cells apoptosis (49). Cells transfected with AMPK small interference (si)RNA were sensitive to cisplatin-induced AKI (60). NAD(P)H: quinone oxidoreductase 1 (NQO1) knockout enhances autophagy in ACHN cells and mice during cisplatin treatment by the AMPK/mTOR signaling pathway (61).

Caspase inhibitor zVAD-fmk prevented the degradation of Atg5, Atg12, and beclin-1 thereby increasing GFP-LC3-II dots in 
Table I. Overview of different studies of autophagy in renal I/R injury.

\begin{tabular}{|c|c|c|c|c|}
\hline Cause of AKI & Model & $\begin{array}{c}\text { Autophagy } \\
\text { modulation method }\end{array}$ & $\begin{array}{l}\text { Role of } \\
\text { autophagy }\end{array}$ & (Refs.) \\
\hline Ischemia 45 min & Male & 3MA Rapa & Protective & $(27)$ \\
\hline Reperfusion $24 \mathrm{~h}$ & Wistar rats & & & \\
\hline $\begin{array}{l}\text { Hypoxia } 24 \mathrm{~h} \\
\text { Reoxygenation 2-24 h }\end{array}$ & TCMK-1 cells & 3MA Rapa & Protective & $(28)$ \\
\hline $\begin{array}{l}\text { Ischemia } 30 \mathrm{~min} \\
\text { reperfusion } 0 \mathrm{~h}-7 \mathrm{~d}\end{array}$ & $\begin{array}{l}\text { Male } \\
\text { BalB/c mice }\end{array}$ & & & \\
\hline $\begin{array}{l}\text { Ischemia } 30 \mathrm{~min} \\
\text { Reperfusion } 3,12,24 \mathrm{~h}\end{array}$ & Male SD rats & 3MA Rapa & Protective & $(29)$ \\
\hline Hypoxic $24 \mathrm{~h}$ & RPTC cells & $\begin{array}{c}\text { GFP-LC3 3MA } \\
\text { ATG5 Beclin shRNA }\end{array}$ & Protective & $(30)$ \\
\hline $\begin{array}{l}\text { Ischemia } 30 \mathrm{~min} \\
\text { Reperfusion } 0,6,24,48 \mathrm{~h}\end{array}$ & C57BL/6 mice & 3MA CQ & & \\
\hline $\begin{array}{l}\text { Ischemia } 25 \mathrm{~min} \\
\text { reperfusion } 24 \mathrm{~h}\end{array}$ & C57BL/6 mice & $\begin{array}{c}\text { CQ Rapa } \\
\text { ATG7 KO }\end{array}$ & Protective & $(31)$ \\
\hline $\mathrm{H}_{2} \mathrm{O}_{2} 200 \mathrm{Mm} 4 \mathrm{~h}$ & LLC-PK1 cells & $\begin{array}{c}\text { Beclin ATG5 siRNA } \\
\text { GFP-LC3 3MA CQ } \\
\text { wortmannin tunicamycin }\end{array}$ & Protective & $(32)$ \\
\hline $\begin{array}{l}\text { Ischemia } 35 \mathrm{~min} \\
\text { Reperfusion } 3,6,12,24,36,48 \mathrm{~h}\end{array}$ & C57BL/6 mice & $\begin{array}{c}\text { ATG5 KO } \\
\text { GFP-LC3 transgenic }\end{array}$ & Protective & $(33)$ \\
\hline $\begin{array}{l}\mathrm{H}_{2} \mathrm{O}_{2} 200,400 \\
600 \mathrm{mM} 4 \mathrm{~h}\end{array}$ & NRK-52E cells & $\begin{array}{c}\text { HSPB1 siRNA } \\
\text { LC3 siRNA } \\
\text { Rapa BAF }\end{array}$ & Protective & $(35)$ \\
\hline $\begin{array}{l}\text { Ischemia } 30 \mathrm{~min} \\
\text { Reperfusion } 0-72 \mathrm{~h}\end{array}$ & Male SD rats & - & & \\
\hline $\begin{array}{l}\text { Antimycin A and } \\
\text { 2-deoxyglucose } 1.5 \mathrm{~h} \\
\text { reperfusion } 24 \mathrm{~h}\end{array}$ & $\begin{array}{l}\text { NRK-52E cells } \\
\text { LLC-PK1 cells }\end{array}$ & $\begin{array}{c}\text { GFP-LC3 } \\
\text { shRNA AMPK 3MA Rapa }\end{array}$ & Protective & $(36)$ \\
\hline $\begin{array}{l}\text { Ischemia } 45 \mathrm{~min} \\
\text { Reperfusion } 96 \mathrm{~h}\end{array}$ & Mice & $\begin{array}{c}\text { LC3-GFP transgenic } \\
\text { Bcl-2/LC3-GFP transgenic }\end{array}$ & Detrimental & $(38)$ \\
\hline $\begin{array}{l}\text { Hypoxia 6-24 h } \\
\mathrm{H}_{2} \mathrm{O}_{2} 500 \mu \mathrm{M} 8-12 \mathrm{~h}\end{array}$ & HK-2 & $\begin{array}{c}\text { 3MA E64d ATG7 siRNA } \\
\text { pepstatin A }\end{array}$ & Protective & $(40)$ \\
\hline Ischemia $30 \mathrm{~min}$ & Male & - & & \\
\hline Reperfusion $0-48 \mathrm{~h}$ & C57BL/6 mice & & & \\
\hline Cold ischemia $48 \mathrm{~h}$ & Mice & GFP-LC3 transgenic & Detrimental & (41) \\
\hline Ischemia 35 min & Male & - & Protective & $(43)$ \\
\hline Reperfusion 1, 3, $7 \mathrm{~d}$ & C57BL/6 mice & & & \\
\hline $\begin{array}{l}\text { Hypoxia } 24 \mathrm{~h} \\
\text { Reoxygenation } 24 \mathrm{~h}\end{array}$ & NRK-52E cells & $\begin{array}{c}\text { Rab11a siRNA } \\
\text { pcDNA3.1-Rab11a }\end{array}$ & Protective & $(44)$ \\
\hline
\end{tabular}

RPTC, renal proximal tubular cell; Rapa, rapamycin; CQ, chloroquine; BAF, bafilomycin A1; 3MA, 3-methyladenine.

LLC-PK1 during cisplatin treatment. However, autophagosome formation and p62 expression were not significantly increased in the presence of zVAD-fmk and chloroquine, demonstrating that zVAD-fmk impaired autophagic flux by blocking the autophagosome clearance (62). zVAD-fmk suppressed lysosomal function and impaired autophagic flux by inhibiting lysosomal cathepsins (63) and calpains $(64,65)$. A similar result is obtained zVAD-fmk prevented beclin-1 cleavage to impair autophagic flux and increase cisplatin-induced cellular injury in a mouse model (62). There is a connection between apoptosis and autophagy, where a signaling pathway that regulates autophagy can also regulate apoptosis (17). Therfore, $10 \mu \mathrm{M}$ cisplatin induced autophagy to maintain cell homeostasis, whereas $50 \mu \mathrm{M}$ cisplatin induced cell apoptosis in NRK-52E cells. However, Rovetta et al (66) demonstrated that ER signaling pathway regulated the balance between autophagy and apoptosis induced by cisplatin. Autophagy mostly served a renoprotective action in cisplatin-induced AKI (Table II). 
Table II. Overview of different studies of autophagy in renal drugs injury.

\begin{tabular}{|c|c|c|c|c|}
\hline Cause of AKI & Model & $\begin{array}{l}\text { Autophagy } \\
\text { modulation method }\end{array}$ & $\begin{array}{c}\text { Role of } \\
\text { autophagy }\end{array}$ & (Refs.) \\
\hline Cisplatin $10-50 \mu \mathrm{M} 24 \mathrm{~h}$ & NRK-52E cells & $\begin{array}{l}\text { Rapa BAF } \\
\text { compound C }\end{array}$ & Protective & $(49)$ \\
\hline Cisplatin $20 \mu \mathrm{M} \mathrm{0-16} \mathrm{h}$ & RPTC & Beclin shRNA Bcl-2 transfection & Protective & $(50)$ \\
\hline $30 \mathrm{mg} / \mathrm{kg} \mathrm{0-3} \mathrm{d}$ & C57BL/6 mice & - & & \\
\hline Cisplatin $10 \mu \mathrm{g} / \mathrm{ml} 48 \mathrm{~h}$ & Primary kidney cells & Compound $\mathrm{C}$ & Protective & $(59)$ \\
\hline $25 \mathrm{mg} / \mathrm{kg} 48 \mathrm{~h}$ & C57BL/6 mice & AMPK siRNA & & \\
\hline Cisplatin $16 \mathrm{mg} / \mathrm{kg} 3 \mathrm{~d}$ & Male Wistar rats & CQ Rapa & Protective & $(60)$ \\
\hline Cisplatin $20 \mu \mathrm{M} 24 \mathrm{~h}$ & ACHN cells & 3MA CQ Rapa & Protective & $(61)$ \\
\hline $18 \mathrm{mg} / \mathrm{kg}$ & C57BL/6 mice & Compound C NQO1-KO & & \\
\hline \multirow[t]{2}{*}{ Cyclosporine A $20 \mu \mathrm{M}$} & HK-2 & BAF & Protective & $(69)$ \\
\hline & TMBIM6 KO mice & - & & \\
\hline
\end{tabular}

RPTC, renal proximal tubular cell; Rapa, rapamycin; CQ, chloroquine; BAF, bafilomycin A1; 3MA, 3-methyladenine; NQO1, quinone oxidoreductase 1 .

Table III. Overview of different studies of autophagy in renal sepsis injury.

\begin{tabular}{llcr}
\hline Cause of AKI & \multicolumn{1}{c}{ Model } & Autophagy modulation method & Role of autophagy \\
\hline LPS $1 \mathrm{mg} / \mathrm{ml} 24 \mathrm{~h}$ & RTEC & Bafilomycin A1 & Protective \\
LPS $15 \mathrm{mg} / \mathrm{kg} 48 \mathrm{~h}$ & Male C57BL/6 mice & ATG7 KO & (72) \\
TNF- $\alpha 2 \mathrm{ng} / \mu 124 \mathrm{~h}$ & NRK-52E cells & siRNAs Atg7 Rapa & Protective \\
CLP $3,6,9,18 \mathrm{~h}$ & male SD rats & - & Protective \\
LPS $10 \mathrm{mg} / \mathrm{kg} 24 \mathrm{~h}$ & Male C57BL/6 mice & CQ PT-Atg7- KO & (74) \\
LPS $1.5 \mathrm{mg} / \mathrm{kg} 48 \mathrm{~h}$ & Male C57BL/6 mice & RFP-EGFP-LC3 & (75) \\
& & mTOR inhibitor & activator of AMPK \\
\end{tabular}

RTEC, renal tubular epithelial cell; Rapa, rapamycin; CQ, chloroquine.

Cyclosporine A (CsA) is an immune-suppressor used in renal allograft transplantation (67). Previous studies demonstrated that CsA induced the accumulation of autophagosomes and inhibited autophagic clearance (68). Yadav et al (69) demonstrated that expression of LC3-II was increased and SQSTM1 accumulation was decreased following CsA treatment in transmembrane BAX inhibitor motif containing 6 (TMBIM6)-expressing HK-2 cells compared to NC cells, suggesting that the autophagic flux was standard in TMBIM6 cells. A similar result was obtained in vivo, in CsA-treated TMBIM6-/- mice where autophagosome formation was increased and the formation and activity of lysosome were decreased (69). The mechanism of TMBIM6-induced autophagy was that it activated PRKAA and suppressed mTORC1 in CsA-treated HK-2 cells. This further demonstrated that TMBIM6 reversed the impaired autophagic flux by stimulating lysosome biogenesis through TFEB activation.

Autophagy in sepsis renal injury. Sepsis-related AKI is an important clinical issue occurring during severe infection including cecal ligation and puncture (CLP) and LPS (70,71). The effect of autophagy in septic AKI remains unclear, compared with the genetic evidence in I/R and cisplatin models (17). Lipopolysaccharide (LPS)-induced accumulation of LC3-II in HPT1 cells derived from human proximal tubular epithelial cells (PTEC) (72). Preincubation of rapamycin decreased tumor necrosis factor (TNF) and induces NRK-52E cell death, whereas the knockdown of Atg7 exaggerated TNF-induced DNA fragmentation (73). This demonstrated that autophagy serves a cytoprotective role in the sepsis-induced AKI. Similar results were found in vivo, LPS induces the accumulation of LC3-positive puncta in GFP-LC3 transgenic mice (74). CLP-induced autophagy was time-dependent in rat, LC3-II was elevated transiently at $3 \mathrm{~h}$ but declined at $9 \mathrm{~h}$ until $18 \mathrm{~h}$ after CLP, renal dysfunction occurred at 9 and $18 \mathrm{~h}$ after CLP (73), indicating that autophagy occurred prior to apoptosis and the decline of autophagy aggravated TNF- $\alpha$-induced cell death. Chloroquine, an inhibitor of lysosomes also aggravates LPS-induced AKI in C57BL/6 mice (74). Tubular injury was more severe in ATG7KO mice than in controls and the 


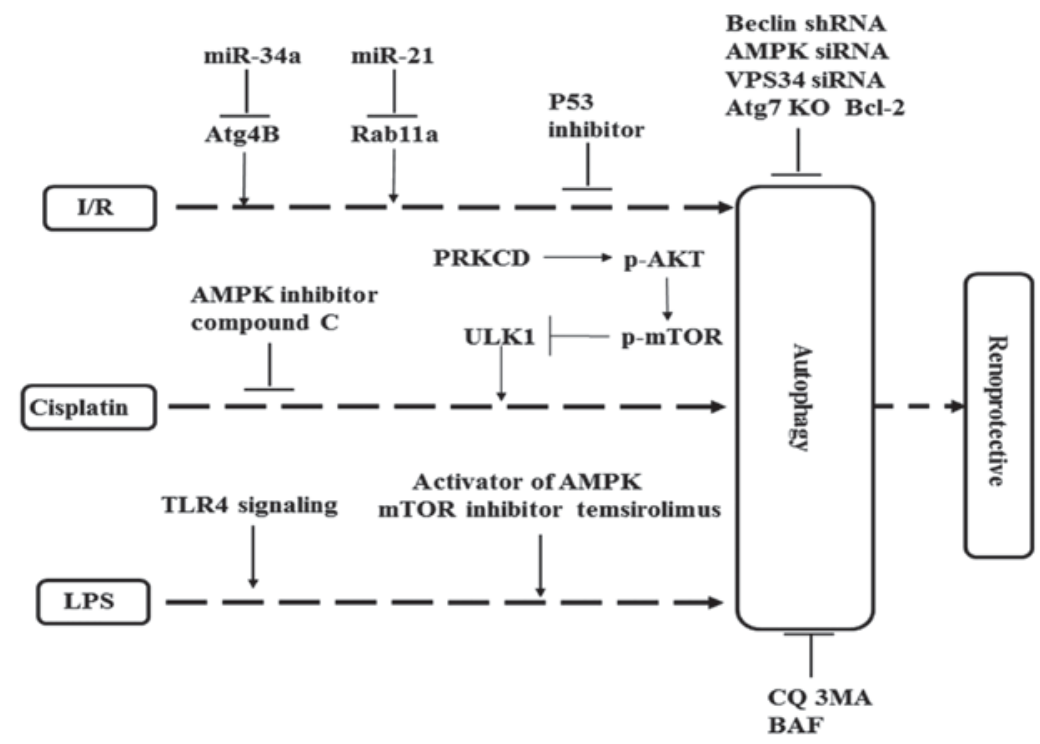

Figure 2. Overview of the protective mechanism of autophagy in AKI. In I/R induced AKI models, miR-34a and miR-21 activate autophagy by direct binding to Atg4B and Rab1la respectively. In cisplatin-induced AKI models, AMPK and p53 inhibitor decrease the autophagy. In addition, the PRKCD also inhibits autophagy by regulating AKT/mTOR signaling pathway. In LPS induced AKI models, TLR4 signaling pathway promotes autophagy and activator of AMPK or inhibitor of mTOR has the same effect on autophagy. Knock down of certain autophagy-associated genes or administration of pharmacological inhibitors of autophagy also inhibits the protective effect of autophagy in AKI. I/R, ischemia/reperfusion; AKI, acute kidney injury; miR, microRNA; Atg4B, cysteine protease ATG4B; Rab11a, Ras-related protein Rab-11A; AMPK, 5' AMP-activated protein kinase; PRKCD, protein kinase C $\delta$ type; AKT, RAC-alpha serine/threonine-protein kinase; mTOR, serine/threonine-protein kinase mTOR; TLR4, toll-like receptor 4.

expression of IL-6 was significantly increased in ATG7KO kidneys compared with controls following LPS treatment (73), indicating that autophagy protected kidneys from CLP and LPS-induced sepsis injury. Leventhal et al (72) reported that LPS-induced autophagy in RTEC was TLR4-dependent, there were no differences in LC3-II accumulation in C57BI $\backslash 10 \mathrm{ScN}$ mice, which was no functional TLR4 compared with saline-injected mice. Autophagy was decreased in adult mice during LPS-induced AKI, administration of the mTOR inhibitor temsirolimus increased autophagy and improved renal function in adult mice during LPS-induced AKI (75). In young mice ( 8 weeks of age), the inhibitor of VPS34 damaged renal function after LPS treatment (75). These results suggest that autophagy serves a renoprotective role irrespective of age (young or aged mice) during LPS treatment (Table III).

\section{MSCs and extracellular vesicles therapy in AKI}

Mesenchymal stem cells (MSCs) are multipotent stem cells isolated from different tissues including bone marrow, umbilical cord, adipose tissue or muscle (76). These cells have self-renewal and multiple differentiation potential including adipocytes, chondrocytes and osteocytes (77). A large number of studies have documented the potential therapeutic effects of MSC, including cardiopathy (78), hepatic diseases (79), and renal injury (80). The therapeutic potential of MSCs includes the anti-inflammatory, antioxidant, anti-fibrotic, anti-apoptotic, pro-angiogenic, stimulation of endogenous progenitor cells, and promotion of cellular reprogramming (78-80). Exosomes derived from MSC have beneficial effects in distinct models of injury. Our previous studies suggested that exosomes derived from human umbilical cord MSCs alleviated liver fibrosis (81), cutaneous wound healing (82), and acute myocardial ischemic injury (83).
MSCs are recruited to injured tissues and release certain cytokines and growth factors, such as insulin-like, hepatocyte and vascular endothelial growth factors, which could activate endogenous cellular repair programs contributing to the growth and survival of endothelial and epithelial tubular cells thus promoting renal angiogenesis and regeneration $(84,85)$. Bruno et al (86) demonstrated that MSC-derived microvesicles express MSC markers and transferr cellular materials to neighboring cells, including RNA and proteins, consequently promoting cell proliferation and inhibited apoptosis.

Human MSCs repair HK2 cell after ischemia injury by stimulating normal reactive oxygen species handling, anti-apoptotic activity, energy production, protein synthesis, cytoskeleton organization and cell proliferation (87). In I/R rats, MSCs repair kidney by anti-inflammatory, anti-apoptotic and by enhancing the repair of peritubular capillaries and tubular epithelial cells (88). Furthermore, extracellular vesicles derived from MSCs alleviate kidney injury through anti-oxidation by strengthening Nrf2/ARE activation in I/R rats (89). BM-MSCs ameliorate cisplatin-induced AKI by increasing Foxp ${ }^{3+}$ T-regulatory cell infiltration in a monkey model (90). Human adipose-derived mesenchymal stem cells protect against cisplatin-induced AKI via anti-apoptotic pathways (91). In a previous study, it demonstrated that human umbilical cord mesenchymal stem cells-derived exosomes decrease cisplatin-induced renal oxidative stress and apoptosis in NRK-52E cells and in rats (92), indicating that MSCs and microvesicles released by MSCs may improve renal injury in AKI.

\section{The role of autophagy in MSCs cell-based therapies}

Autophagy plays a critical role in MSCs-based therapy of tissues injury. Hypoxia and heat shock pretreatment enhance 
survival in BM-MSCs and increase the therapeutic potential of the stem cell by increasing autophagy, providing a novel strategy to improve MSC-based therapies $(93,94)$.

Bone marrow (BM)-MSCs alleviate chronic high glucose-induced injury in INS-1 cells (95) and reduce the severity of lung I/R injury in human pulmonary microvascular endothelial cells (HPMVECs) (96) by enhanced autophagic activity. Similar results are presented in vivo, where BM-MSCs promote the recovery of pancreatic damage in T2D rats (95) and reduce the severity of lung I/R injury in C57BL/6J mice (96). Shin et al (97) demonstrated that MSCs significantly enhance autophagy and the clearance of amyloid- $\beta$ in Alzheimer disease models to increase neuronal survival against $A \beta$ toxicity. In a Parkinsonian model, BM-MSCs increase the cell viability and reduce $\alpha$-synuclein by upregulating autophagolysosome formation (98). Tonsil-derived MSCs ameliorate liver fibrosis via the downregulation of TGF- $\beta$ and autophagy activation (99). These findings support the protective effect of autophagy in MSCs, thereby repairing the pancreas, lung, nervous diseases. In our previous studies, it was demonstrated that human umbilical cord mesenchymal stem cell-derived exosomes prevent cisplatin-induced AKI by autophagy (100) which providing a novel strategy of MSC-based therapy for AKI.

\section{Conclusions}

In conclusion, autophagy is induced in kidneys in response to AKI, autophagy in AKI is multifaceted and complex, and it can protect against kidney injury or promote cell death depending on experimental conditions (17). The activity of autophagy is time-dependent. In the early stages of renal injury, autophagy contributes to cell survival, whereas in later stages, autophagy may activate apoptosis signaling pathways sequentially promoting cell death and renal function injury, but the mechanism remains unknown. Autophagy and apoptosis share similar regulators and are mutually inhibitory (101). Many factors that activate autophagy also activate cell apoptosis, which usually precedes cell apoptosis (17). Several critical signaling pathways positively regulate autophagy and apoptosis, such as the tumor suppressor p53, bcl-2 family, death-associated protein kinases and c-Jun $\mathrm{N}$ terminal kinases (101). In the model of cisplatin-induced nephrotoxicity, PRKCD suppressed autophagy and promoted renal cell death by AKT/mTOR signal pathway (102). The possible protective mechanism of autophagy in AKI is summarized in Fig. 2. Autophagic flux is frequently defined as a measure of autophagic degradation activity. Continuous observation autophagy is imperative, and to assess the efficiency of the autophagic flux is necessarily in measuring autophagic degradation activity. However, the molecules participating in the autophagosome formation and the regulating mechanism are not known. The signaling pathways, which have been reported in AKI models, such as AMPK and mTOR, are critical in inducing and regulating autophagy but these are also poorly understood.

Pharmacological inhibitors (3-MA or bafilomycin A or wortmannin) or inducers (Rapa) of autophagy are non-specific for autophagy (17). It is necessary to find autophagy inducers in proximal tubules and examine their effects in models of AKI. A comprehensive understanding of autophagy may improve renal function and prevent AKI progression.
MSC-based therapies have been extensively studied as a potential treatment for several diseases (78-80). However, our understanding of the regulatory mechanisms of MSCs or MSC-derived vesicles in kidney disease, remain to be fully elucidated. Autophagy serves a key role in MSCs-based therapy, but effects of autophagy in AKI, which are repaired by MSCs are not very clear. Therefore, elucidating its role may provide a novel approach towards the therapy of AKI.

\section{Acknowledgements}

The present study was supported by the National Natural Science Foundation of China (grant no. 81272481), the Major Research Plan of Jiangsu Higher Education (grant no. 15KJA320001) and a project funded by the Priority Academic Program Development of Jiangsu Higher Education Institutions.

\section{References}

1. Qian M, Fang X and Wang X: Autophagy and inflammation. Clin Transl Med 6: 24, 2017.

2. Tomiyama R, Takakura K, Takatou S, Le TM Nishiuchi T, Nakamura Y, Konishi T, Matsugo S and Hori O: 3,4-dihydroxybenzalacetone and caffeic acid phenethyl ester induce preconditioning ER stress and autophagy in SH-SY5Y cells. J Cell Physiol 233: 1671-1684, 2018.

3. Antikainen H, Driscoll M, Haspel G and Dobrowolski R: TOR-mediated regulation of metabolism in aging. Aging Cell 16: 1219-1233, 2017.

4. Germic N,Stojkov D, Oberson K, Yousefi S and Simon HU: Neither eosinophils nor neutrophils require ATG5-dependent autophagy for extracellular DNA trap formation. Immunology 152: 517-525, 2017.

5. Long M, Li X, Li L, Dodson M, Zhang DD and Zheng H: Multifunctional p62 effects underlie diverse metabolic diseases. Trends Endocrinol Metab 28: 818-830, 2017.

6. Hu ZY, Chen B, Zhang JP and Ma YY: Up-regulation of autophagy-related gene 5 (ATG5) protects dopaminergic neurons in a zebrafish model of Parkinson's disease. J Biol Chem 292: 18062-18074, 2017.

7. Choi HS, Jeong EH, Lee TG, Kim SY, Kim HR and Kim CH: Autophagy inhibition with monensin enhances cell cycle arrest and apoptosis induced by mTOR or epidermal growth factor receptor inhibitors in lung cancer cells. Tuberc Respir Dis (Seoul) 75: 9-17, 2013.

8. Wang Z and Choi ME: Autophagy in kidney health and disease. Antioxid Redox Signal 20: 519-537, 2014.

9. Huber TB, Edelstein CL, Hartleben B, Inoki K, Jiang M, Koya D, Kume S, Lieberthal W, Pallet N, Quiroga A, et al: Emerging role of autophagy in kidney function, diseases and aging. Autophagy 8: 1009-1031, 2012.

10. He L, Wei Q, Liu J, Yi M, Liu Y, Liu H, Sun L, Peng Y, Liu F, Venkatachalam MA and Dong Z: AKI on CKD: Heightened injury, suppressed repair and the underlying mechanisms. Kidney Int 92: 1071-1083, 2017.

11. Trongtrakul K, Sawawiboon C, Wang AY, Chitsomkasem A, Limphunudom P, Kurathong S, Prommoon S, Trakarnvanich T and Srisawat N: Acute kidney injury in critically Ill surgical patients: Epidemiology, risk factors and outcomes. Nephrology (Carlton) 2017.

12. Deng X, Xie Y and Zhang A: Advance of autophagy in chronic kidney diseases. Ren Fail 39: 306-313, 2017.

13. Levine B and Klionsky DJ: Development by self-digestion: Molecular mechanisms and biological functions of autophagy. Dev Cell 6: 463-477, 2004.

14. Mizushima N and Komatsu M: Autophagy: Renovation of cells and tissues. Cell 147: 728-741, 2011.

15. Ravikumar B, Sarkar S, Davies JE, Futter M, Garcia-Arencibia M, Green-Thompson ZW, Jimenez-Sanchez M, Korolchuk VI, Lichtenberg M, Luo S, et al: Regulation of mammalian autophagy in physiology and pathophysiology. Physiol Rev 90: 1383-1435, 2010 . 
16. Sekito T, Kawamata T, Ichikawa R, Suzuki K and Ohsumi Y: Atg17 recruits Atg9 to organize the pre-autophagosomal structure. Genes Cells 14: 525-538, 2009.

17. Livingston MJ and Dong Z: Autophagy in acute kidney injury. Semin Nephrol 34: 17-26, 2014.

18. Mi N, Chen Y, Wang S, Chen M, Zhao M, Yang G, Ma M, Su Q, Luo S, Shi J, et al: CapZ regulates autophagosomal membrane shaping by promoting actin assembly inside the isolation membrane. Nat Cell Biol 17: 1112-1123, 2015.

19. Sureshbabu A, Ryter SW and Choi ME: Oxidative stress and autophagy: Crucial modulators of kidney injury. Redox Biol 4 : 208-214, 2015.

20. Ravanan P, Srikumar IF and Talwar P: Autophagy: The spotlight for cellular stress responses. Life Sci 188: 53-67, 2017.

21. Tang JC, Feng YL, Liang X and Cai XJ: Autophagy in 5-fluorouracil therapy in gastrointestinal cancer: Trends and challenges. Chin Med J (Engl) 129: 456-463, 2016.

22. Degenhardt K, Mathew R, Beaudoin B, Bray K, Anderson D, Chen G, Mukherjee C, Shi Y, Gélinas C, Fan Y, et al: Autophagy promotes tumor cell survival and restricts necrosis, inflammation and tumorigenesis. Cancer Cell 10: 51-64, 2006.

23. Pla A, Pascual M and Guerri C: Autophagy constitutes a protective mechanism against ethanol toxicity in mouse astrocytes and neurons. PLoS One 11: e0153097, 2016.

24. Shirakabe A, Ikeda Y, Sciarretta S, Zablocki DK and Sadoshima J: Aging and autophagy in the heart. Circ Res 118: 1563-1576, 2016.

25. Wang XY, Yang H, Wang MG, Yang DB, Wang ZY and Wang L: Trehalose protects against cadmium-induced cytotoxicity in primary rat proximal tubular cells via inhibiting apoptosis and restoring autophagic flux. Cell Death Dis 8: e3099, 2017.

26. de Almeida DC, Donizetti-OliveiraC, Barbosa-Costa P, Origassa CS and Câmara NO: In search of mechanisms associated with mesenchymal stem cell-based therapies for acute kidney injury. Clin Biochem Rev 34: 131-144, 2013.

27. Zhang YL, Zhang J, Cui LY and Yang S: Autophagy activation attenuates renal ischemia-reperfusion injury in rats. Exp Biol Med (Maywood) 240: 1590-1598, 2015.

28. Guan X, Qian Y, Shen Y, Zhang L, Du Y, Dai H, Qian J and Yan Y: Autophagy protects renal tubular cells against ischemia/reperfusion injury in a time-dependent manner. Cell Physiol Biochem 36: 285-298, 2015.

29. Ling H, Chen H, Wei M, Meng X, Yu Y and Xie K: The effect of autophagy on inflammation cytokines in renal ischemia/reperfusion injury. Inflammation 39: 347-356, 2016.

30. Jiang M, Liu K, Luo J and Dong Z: Autophagy is a renoprotective mechanism during in vitro hypoxia and in vivo ischemia-reperfusion injury. Am J Pathol 176: 1181-1192, 2010.

31. Jiang M, Wei Q, Dong G, Komatsu M, Su Y and Dong Z: Autophagy in proximal tubules protects against acute kidney injury. Kidney Int 82: 1271-1283, 2012.

32. Chandrika BB, Yang C, Ou Y, Feng X, Muhoza D, Holmes AF, Theus S, Deshmukh S, Haun RS and Kaushal GP: Endoplasmic reticulum stress-induced autophagy provides cytoprotection from chemical hypoxia and oxidant injury and ameliorates renal ischemia-reperfusion injury. PLoS One 10: e0140025, 2015.

33. Kimura T, Takabatake Y, Takahashi A, Kaimori JY, Matsui I, Namba T, Kitamura H, Niimura F, Matsusaka T, Soga T, et al: Autophagy protects the proximal tubule from degeneration and acute ischemic injury. J Am Soc Nephrol 22: 902-913, 2011.

34. Liu S, Hartleben B, Kretz O, Wiech T, Igarashi P, Mizushima N, Walz G and Huber TB: Autophagy plays a critical role in kidney tubule maintenance, aging and ischemia-reperfusion injury. Autophagy 8: 826-837, 2012 .

35. Matsumoto $T$, Urushido $M$, Ide $H$, Ishihara M, Hamada-Ode $K$, Shimamura Y, Ogata K, Inoue K, Taniguchi Y, Taguchi T, et al: Small heat shock protein beta-1 (HSPB1) is upregulated and regulates autophagy and apoptosis of renal tubular cells in acute kidney injury. PLoS One 10: e0126229, 2015.

36. Wang LT, Chen BL, Wu CT, Huang KH, Chiang CK and HwaLiu S:Protective role of AMP-activated protein kinase-evoked autophagy on an in vitro model of ischemia/reperfusion-induced renal tubular cell injury. PLoS One 8: e79814, 2013.

37. Decuypere JP, Ceulemans LJ, Agostinis P, Monbaliu D, Naesens M, Pirenne J and Jochmans I: Autophagy and the kidney: Implications for ischemia-reperfusion injury and therapy. Am J Kidney Dis 66: 699-709, 2015.

38. Isaka Y, Suzuki C, Abe T, Okumi M, Ichimaru N, Imamura R, Kakuta Y, Matsui I, Takabatake Y, Rakugi H, et al: Bcl-2 protects tubular epithelial cells from ischemia/reperfusion injury by dual mechanisms. Transplant Proc 41: 52-54, 2009.
39. Chien CT, Shyue SK and Lai MK: Bcl-xL augmentation potentially reduces ischemia/reperfusion induced proximal and distal tubular apoptosis and autophagy. Transplantation 84: 1183-1190, 2007.

40. Suzuki C, Isaka Y, Takabatake Y, Tanaka H, Koike M, Shibata M, Uchiyama Y, Takahara S and Imai E: Participation of autophagy in renal ischemia/reperfusion injury. Biochem Biophys Res Commun 368: 100-106, 2008.

41. Turkmen K, Martin J, Akcay A, Nguyen Q, Ravichandran K, Faubel S, Pacic A, Ljubanović D, Edelstein CL and Jani A: Apoptosis and autophagy in cold preservation ischemia. Transplantation 91: 1192-1197, 2011.

42. Yu SY, Dong B, Zhou SH and Tang L: LncRNA MALAT1: A potential regulator of autophagy in myocardial ischemia-reperfusion injury. Int J Cardiol 247: 25, 2017.

43. Liu XJ, Hong Q, Wang Z, Yu YY, Zou X and Xu LH MicroRNA-34a suppresses autophagy in tubular epithelial cells in acute kidney injury. Am J Nephrol 42: 168-175, 2015.

44. Liu X, Hong Q, Wang Z, Yu Y, Zou X and Xu L: MiR-21 inhibits autophagy by targeting Rablla in renal ischemia/reperfusion. Exp Cell Res 338: 64-69, 2015.

45. Arany I and Safirstein RL: Cisplatin nephrotoxicity. Semin Nephrol 23: 460-464, 2003

46. Pabla N and Dong Z: Cisplatin nephrotoxicity: Mechanisms and renoprotective strategies. Kidney Int 73: 994-1007, 2008.

47. Levine B and Yuan J: Autophagy in cell death: An innocent convict? J Clin Invest 115: 2679-2688, 2005.

48. Maiuri MC, Zalckvar E, Kimchi A and Kroemer G: Self-eating and self-killing: Crosstalk between autophagy and apoptosis. Nat Rev Mol Cell Biol 8: 741-752, 2007.

49. Liu H, Gu LB, Tu Y, Hu H, Huang YR and Sun W: Emodin ameliorates cisplatin-induced apoptosis of rat renal tubular cells in vitro by activating autophagy. Acta Pharmacol Sin 37: 235-245, 2016

50. Periyasamy-Thandavan S, Jiang M, Wei Q, Smith R, Yin XM and Dong Z: Autophagy is cytoprotective during cisplatin injury of renal proximal tubular cells. Kidney Int 74: 631-640, 2008.

51. Fang B and Xiao H: Rapamycin alleviates cisplatin-induced ototoxicity in vivo. Biochem Biophys Res Commun 448: 443-447, 2014

52. Sprowl JA, Lancaster CS, Pabla N, Hermann E, Kosloske AM, Gibson AA, Li L, Zeeh D, Schlatter E, Janke LJ, et al: Cisplatin-induced renal injury is independently mediated by OCT2 and p53. Clin Cancer Res 20: 4026-4035, 2014.

53. Cummings BS and Schnellmann RG: Cisplatin-induced renal cell apoptosis: Caspase 3-dependent and -independent pathways. J Pharmacol Exp Ther 302: 8-17, 2002.

54. Jiang M, Wei Q, Wang J, Du Q, Yu J, Zhang L and Dong Z Regulation of PUMA-alpha by p53 in cisplatin-induced renal cell apoptosis. Oncogene 25: 4056-4066, 2006.

55. Jiang M, Yi X, Hsu S, Wang CY and Dong Z: Role of p53 in cisplatin-induced tubular cell apoptosis: Dependence on p53 transcriptional activity. Am J Physiol Renal Physiol 287: F1140-F1147, 2004.

56. Seth R, Yang C, Kaushal V, Shah SV and Kaushal GP p53-Dependent caspase-2 activation in mitochondrial release of apoptosis-inducing factor and its role in renal tubular epithelial cell injury. J Biol Chem 280: 31230-31239, 2005.

57. Wei Q, Dong G, Franklin J and Dong Z: The pathological role of Bax in cisplatin nephrotoxicity. Kidney Int 72: 53-62, 2007.

58. Wei Q, Dong G, Yang T, Megyesi J, Price PM and Dong Z: Activation and involvement of p53 in cisplatin-induced nephrotoxicity. Am J Physiol Renal Physiol 293: F1282-F1291, 2007.

59. Feng Z, Zhang H, Levine AJ and Jin S: The coordinate regulation of the p53 and mTOR pathways in cells. Proc Natl Acad Sci USA 102: 8204-8209, 2005.

60. Wei L, Chen W, Zou Y, Huang H, Pan B, Jin S, Huang R, Nie S and Kong G: AMP-activated protein kinase regulates autophagic protection against cisplatin-induced tissue injury in the kidney. Genet Mol Res 14: 12006-12015, 2015.

61. Kim TW, Kim YJ, Kim HT, Park SR, Lee MY, Park YD, Lee $\mathrm{CH}$ and Jung JY: NQO1 deficiency leads enhanced autophagy in cisplatin-induced acute kidney injury through the AMPK/TSC2/mTOR signaling pathway. Antioxid Redox Signal 24: 867-883, 2016.

62. Herzog C, Yang C, Holmes A and Kaushal GP: zVAD-fmk prevents cisplatin-induced cleavage of autophagy proteins but impairs autophagic flux and worsens renal function. Am J Physiol Renal Physiol 303: F1239- F1250, 2012. 
63. Scaringi L, Cornacchione P, Ayroldi E, Corazzi L, Capodicasa E, Rossi R and Marconi P: Omeprazole induces apoptosis in jurkat cells. Int J Immunopathol Pharmacol 17: 331-342, 2004.

64. Bizat N, Galas MC, Jacquard C, Boyer F, Hermel JM, Schiffmann SN, Hantraye P, Blum D and Brouillet E: Neuroprotective effect of zVAD against the neurotoxin 3 -nitropropionic acid involves inhibition of calpain. Neuropharmacology 49: 695-702, 2005.

65. Madden DT, Egger L and Bredesen DE: A calpain-like protease inhibits autophagic cell death. Autophagy 3: 519-522, 2007.

66. Rovetta F, Stacchiotti A, Consiglio A, Cadei M, Grigolato PG Lavazza A, Rezzani R and Aleo MF: ER signaling regulation drives the switch between autophagy and apoptosis in NRK-52E cells exposed to cisplatin. Exp Cell Res 318: 238-250, 2012.

67. Xu QX, Qiu XY, Jiao Z, Zhang M and Zhong MK: FOXP3 rs3761549 polymorphism predicts long-term renal allograft function in patients receiving cyclosporine-based immunosuppressive regimen. Gene, 2017 (Epub ahead of print).

68. Lim SW, Hyoung BJ, Piao SG, Doh KC, Chung BH and Yang CW: Chronic cyclosporine nephropathy is characterized by excessive autophagosome formation and decreased autophagic clearance. Transplantation 94: 218-225, 2012.

69. Yadav RK, Lee GH, Lee HY, Li B, Jung HE, Rashid HO, Choi MK, Yadav BK, Kim WH, Kim KW, et al: TMBIM6 (transmembrane BAX inhibitor motif containing 6) enhances autophagy and reduces renal dysfunction in a Cyclosporine A-induced nephrotoxicity model. Autophagy 11: 1760-1774, 2015 .

70. Yegenaga I, Tuglular S, Ari E, Etiler N, Baykara N, Torlak S, Acar S, Akbas T, Toker K and Solak ZM: Evaluation of sepsis/systemic inflammatory response syndrome, acute kidney injury and RIFLE criteria in two tertiary hospital intensive care units in Turkey. Nephron Clin Pract 115: c276-c282, 2010.

71. Schrier RW and Wang W: Acute renal failure and sepsis. N Engl J Med 351: 159-169, 2004

72. Leventhal JS, Ni J, Osmond M, Lee K, Gusella GL, Salem F and Ross MJ: Autophagy limits endotoxemic acute kidney injury and alters renal tubular epithelial cell cytokine expression. PLoS One 11: e0150001, 2016.

73. Hsiao HW, Tsai KL, Wang LF, Chen YH, Chiang PC, Chuang SM and Hsu C: The decline of autophagy contributes to proximal tubular dysfunction during sepsis. Shock 37: 289-296, 2012

74. Mei S, Livingston M, Hao J, Li L, Mei C and Dong Z: Autophagy is activated to protect against endotoxic acute kidney injury. Sci Rep 6: 22171, 2016.

75. Howell GM, Gomez H, Collage RD, Loughran P, Zhang X, Escobar DA, Billiar TR, Zuckerbraun BS and Rosengart MR: Augmenting autophagy to treat acute kidney injury during endotoxemia in mice. PLoS One 8: e69520, 2013

76. Kern S, Eichler H, Stoeve J, Klüter H and Bieback K Comparative analysis of mesenchymal stem cells from bone marrow, umbilical cord blood, or adipose tissue. Stem Cells 24 1294-1301, 2006

77. Caplan AI: Mesenchymal stem cells. J Orthop Res 9: 641-650, 1991.

78. Golpanian S, Wolf A, Hatzistergos KE and Hare JM: Rebuilding the damaged heart: Mesenchymal stem cells, cell-based therapy and engineered heart tissue. Physiol Rev 96: 1127-1168, 2016.

79. Gazdic M, Arsenijevic A, Markovic BS, Volarevic A, Dimova I, Djonov V, Arsenijevic N, Stojkovic M and Volarevic V: Mesenchymal stem cell-dependent modulation of liver diseases Int J Biol Sci 13: 1109-1117, 2017.

80. Chen C and Hou J: Mesenchymal stem cell-based therapy in kidney transplantation. Stem Cell Res Ther 7: 16, 2016

81. Li T, Yan Y, Wang B, Qian H, Zhang X, Shen L, Wang M, Zhou Y, Zhu W, Li W and Xu W: Exosomes derived from human umbilical cord mesenchymal stem cells alleviate liver fibrosis. Stem Cells Dev 22: 845-854, 2013.

82.Zhang B, Wang M, Gong A, Zhang X, Wu X, Zhu Y, Shi H, Wu L, Zhu W, Qian $\mathrm{H}$ and $\mathrm{Xu} \mathrm{W}$ : HucMSC-exosome mediated-Wnt4 signaling is required for cutaneous wound healing. Stem Cells 33: 2158-2168, 2015

83. Zhao Y, Sun X, Cao W, Ma J, Sun L, Qian H, Zhu W and Xu W: Exosomes derived from human umbilical cord mesenchyma stem cells relieve acute myocardial ischemic injury. Stem Cells Int 2015: 761643, 2015.
84. Meirelles Lda S, Fontes AM, Covas DT and Caplan AI Mechanisms involved in the therapeutic properties of mesenchymal stem cells. Cytokine Growth Factor Rev 20: 419-427, 2009.

85. Tögel F, Zhang P, Hu Z and Westenfelder C: VEGF is a mediator of the renoprotective effects of multipotent marrow stromal cells in acute kidney injury. J Cell Mol Med 13: 2109-2114, 2009.

86. Bruno S, Grange C, Collino F, Deregibus MC, Cantaluppi V, Biancone L, Tetta $\mathrm{C}$ and Camussi G: Microvesicles derived from mesenchymal stem cells enhance survival in a lethal model of acute kidney injury. PLoS One 7: e33115, 2012.

87. da Costa MR, Pizzatti L, Lindoso RS, Sant'Anna JF, DuRocher B, Abdelhay E and Vieyra A: Mechanisms of kidney repair by human mesenchymal stromal cells after ischemia: A comprehensive view using label-free MS(E). Proteomics 14: 1480-1493, 2014.

88. Xing L, Cui R, Peng L, Ma J, Chen X, Xie RJ and Li B: Mesenchymal stem cells, not conditioned medium, contribute to kidney repair after ischemia-reperfusion injury. Stem Cell Res Ther 5: 101, 2014.

89. Zhang G, Zou X, Huang Y, Wang F, Miao S, Liu G, Chen M and Zhu Y: Mesenchymal stromal cell-derived extracellular vesicles protect against acute kidney injury through anti-oxidation by enhancing Nrf2/ARE activation in rats. Kidney Blood Press Res 41: 119-128, 2016.

90. Moghadasali R, Azarnia M, Hajinasrollah M, Arghani H, Nassiri SM, Molazem M, Vosough A, Mohitmafi S, Najarasl M, Ajdari Z, et al: Intra-renal arterial injection of autologous bone marrow mesenchymal stromal cells ameliorates cisplatin-induced acute kidney injury in a rhesus Macaque mulatta monkey model. Cytotherapy 16: 734-749, 2014.

91. Zhou Y, Xu H, Xu W, Wang B, Wu H, Tao Y, Zhang B, Wang M, Mao F, Yan Y, et al: Exosomes released by human umbilical cord mesenchymal stem cells protect against cisplatin-induced renal oxidative stress and apoptosis in vivo and in vitro. Stem Cell Res Ther 4: 34, 2013.

92. Yao W, Hu Q, Ma Y, Xiong W, Wu T, Cao J and Wu D: Human adipose-derived mesenchymal stem cells repair cisplatin-induced acute kidney injury through antiapoptotic pathways. Exp Ther Med 10: 468-476, 2015.

93. Zhang W, Liu L, Huo Y, Yang Y and Wang Y: Hypoxia-pretreated human MSCs attenuate acute kidney injury through enhanced angiogenic and antioxidative capacities. Biomed Res Int 2014 462472,2014

94. Qiao PF, Yao L, Zhang XC, Li GD and Wu DQ: Heat shock pretreatment improves stem cell repair following ischemia-reperfusion injury via autophagy. World J Gastroenterol 21 : $12822-12834,2015$

95. Zhao K, Hao H, Liu J, Tong C, Cheng Y, Xie Z, Zang L, Mu Y and Han W: Bone marrow-derived mesenchymal stem cells ameliorate chronic high glucose-induced $\beta$-cell injury through modulation of autophagy. Cell Death Dis 6: e1885, 2015.

96. Li J, Zhou J, Zhang D, Song Y, She J and Bai C: Bone marrow-derived mesenchymal stem cells enhance autophagy via $\mathrm{PI} 3 \mathrm{~K} / \mathrm{AKT}$ signaling to reduce the severity of ischaemia/reperfusion-induced lung injury. J Cell Mol Med 19: 2341-2351, 2015.

97. Shin JY, Park HJ, Kim HN, Oh SH, Bae JS, Ha HJ and Lee PH: Mesenchymal stem cells enhance autophagy and increase $\beta$-amyloid clearance in Alzheimer disease models. Autophagy 10: 32-44, 2014.

98. Park HJ, Shin JY, Kim HN, Oh SH and Lee PH: Neuroprotective effects of mesenchymal stem cells through autophagy modulation in a parkinsonian model. Neurobiol Aging 35: 1920-1928, 2014

99. Park M, Kim YH, Woo SY, Lee HJ, Yu Y, Kim HS, Park YS Jo I, Park JW, Jung SC, et al: Tonsil-derived mesenchymal stem cells ameliorate $\mathrm{CCl} 4$-induced liver fibrosis in mice via autophagy activation. Sci Rep 5: 8616, 2015.

100. Wang B, Jia H, Zhang B, Wang J, Ji C, Zhu X, Yan Y, Yin L, $\mathrm{Yu}$ J, Qian $\mathrm{H}$ and $\mathrm{Xu}$ W: Pre-incubated with hucMSC-Exosomes prevent cisplatin- induced nephrotoxicity by activating autophagy. Stem Cell Res Ther 8: 75, 2017.

101. Fougeray S and Pallet N: Mechanisms and biological functions of autophagy in diseased and ageing kidneys. Nat Rev Nephrol 11: 34-45, 2015.

102. Zhang D, Xu X and Dong Z: PRKCD/PKCo contributes to nephrotoxicity during cisplatin chemotherapy by suppressing autophagy. Autophagy 13: 631-632, 2017. 